\title{
Disruptive Technology in Digital Notice Board using Flutter
}

\author{
Anirudh Singh Sanger', Tanmay Prasad², Yashwant Singh ${ }^{3}$, Rahul Jha ${ }^{4}$, Sandeep Rao ${ }^{5}$, \\ Vaibhav Sharma ${ }^{6}$, Dr. Manish Mukhija ${ }^{7}$ \\ ${ }^{1,2,3,4,5,6}$ Student, Department of Computer Science \& Engineering, AIET, Jaipur, Rajasthan
}

${ }^{7}$ Associate Professor, Department of Computer Science \& Engineering, AIET, Jaipur, Rajasthan anirudhsinghsanger@gmail.com, prasad.tanmay4@gmail, akaatsukhi@gmail.com, rahulkrjha2018@gmail.com, sandeepraw121@gmail.com, shotriyav25112000@gmail.com, manishkrmukhija82@gmail.com

\section{ABSTRACT}

In early days, notice boards were used to place notices which is a very hard process. First a teacher has to make a notice on his computer and edit to make it attractive then he must get it approved by the HOD. Then when it gets approved, he must print it then the teacher must go to every notice board and physically pin the notice on the notice board Which is a very hard and time-consuming process. In order to make this experience easy we are proposing a digital notice board Which will make the process very easy and very efficient. Our main aim is to make information easy to access to students and at the same time make it easy for teachers to build a notice using their phones and the templates provided on the app.

Keyword - Digital Notice board, Raspberry Pi, Flutter, Dart, Application.

\section{INTRODUCTION}

Globally till this date most of the schools and colleges still use the traditional notice board which is a very hard to maintain and takes a lot of time to maintain and put a notice on the notice board [1]. In this paper we are proposing to make a digital notice board which will be very easy to maintain, and a notice can be up and running in matter of seconds Which will help both teachers and students to consume the information on the notice very effectively. So how this works is there will be an LCD screen which will be used as a notice board, and it will be connected to a raspberry pi which will act as a brain of the notice board. The Raspberry pi Would be connected to the internet $[2,3]$. That will enable us to upload notices or edit the notice board from anywhere from the world. So, for the software side we will be using flutter which is a cross platform application building software. We will be building the mobile apps on mobile using flutter. And connect it with raspberry pi using flutter on Raspbian OS [4]. So, when all is connected then teachers can post and edit the notices board from their app itself. This will help teachers to consume less time and use their time very effectively $[5,6]$. Block diagram of digital notice board is depicted in figure 1 .

\section{SOFTWARE REQUIREMENTS}

\section{Flutter}

Flutter is cross-platform UI Development framework to develop application natively for mobile, web, desktop and embedded device with a single codebase $[7,8]$. There is no need of external markup language like html or $\mathrm{xml}$, all UI and logic part is done in single programming language called Dart. Figure 2 shows the logo of flutter. 


\section{Flutter}

Fig 2: Flutter Logo

\section{Dart}

Dart is general purpose programming language which is compiled natively on all mobile and desktop platform and on web it is compiled into JavaScript $[9,10]$. It can be also used in embedded system. In flutter dart is responsible for drawing every pixel on screen rathe then utilizing native component. Hence it doesn't rely on any type of platform bridge to draw UI. Figure 3 shows the wireframe app.
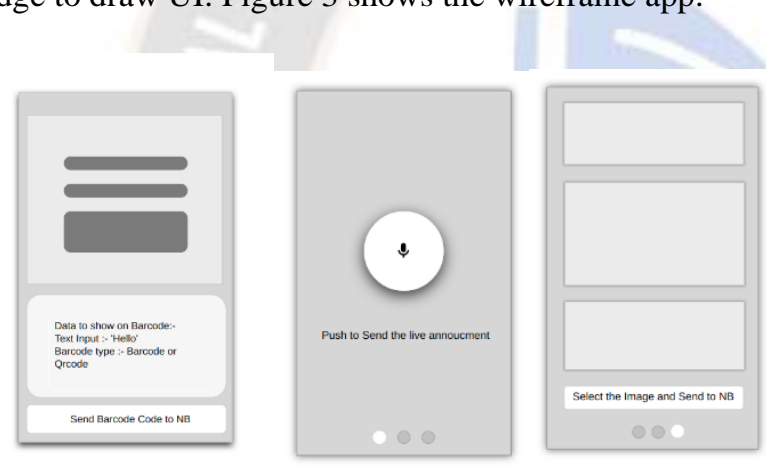
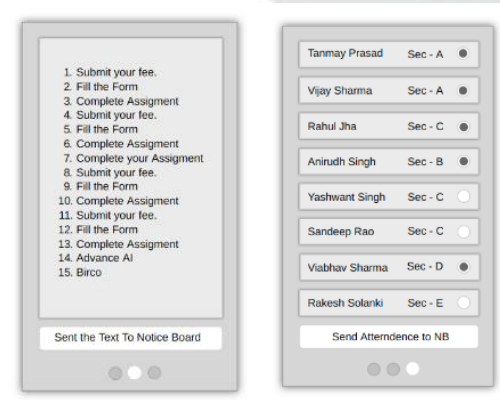

Fig 3: App Wireframe

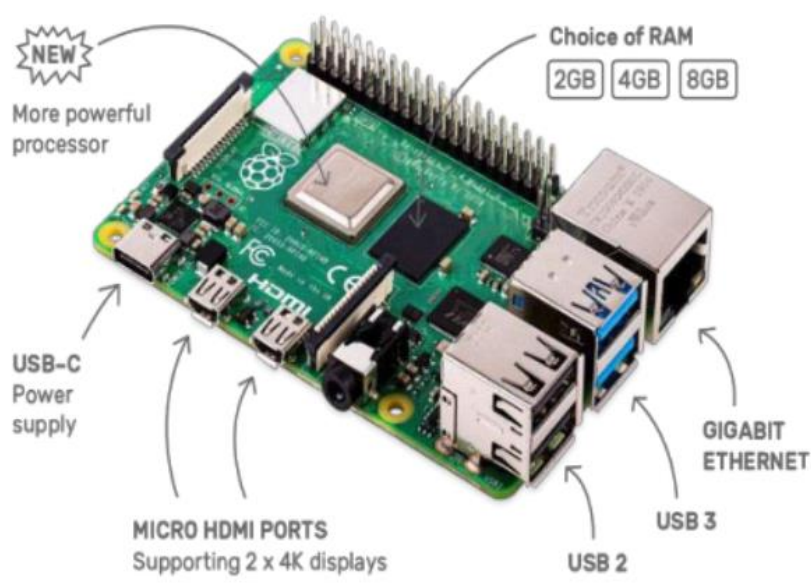

Fig 4: Raspberry pi 4 model B

\section{LCD Monitor}

LCD is a full HD screen which will be 1080p with efficient brightness which will be easy to read and pleasing to the eyes with good viewing angles so that the notice is visible at every angle. This LCD will be used as the notice board, and it can be connected with the raspberry pi using HDMI cable to display on it [13]. Figure 5 shows the LCD screen for the notice board.

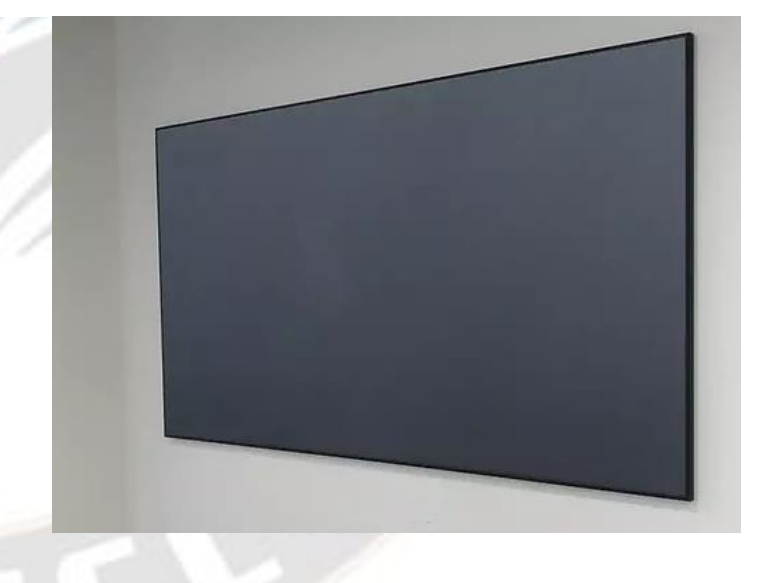

Fig 5: LCD screen for Notice board

\section{Advantage}

Most significant advantage of the digital board is that these can pe used in any scenarios like in office to display notices and in many more places like any store etc. Setting up a digital notice board is not expensive. With few thousand rupees we can make a digital notice board where we can share unlimited notices building and displaying [14]. Digital notice board helps in saving the environment by not using paper at all and also saves time which was consumed in putting up the physical notices. The app in which we make notices has many templates which makes it easy for 
making the notices and updating in the notice board [15]. Figure 6 shows the activity diagram which is being followed.

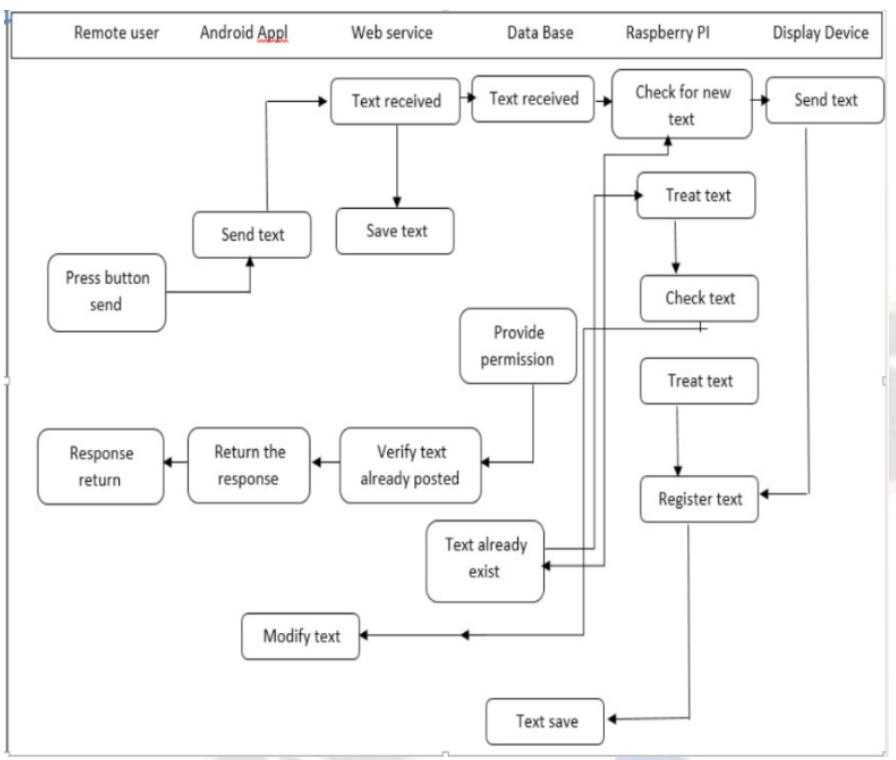

Fig 6: Activity Diagram

\section{Conclusion}

Now as we know world is moving towards digital transformation so we should use new techniques to bring digitalization in every field and this was the part notice board which no one was bringing any innovation to it so we have proposed this idea to make it easy for teachers to make notes and upload it to the notice board and make it easy for students to consume the notice in fast and efficient way. Wireless transmission of the information enables teachers to upload notices from anywhere from the world. It saves time, cost of cables, time which was consumed during physical notice board. In this digital notice board multimedia can also be used like images or video on the notice board which was not possible on the physical notice board.

\section{References}

[1] Mr. Ramchandra K. Gurav, Mr. Rohit Jagtap, "Wireless Digital Notice Board Using GSM Technology", International Research Journal of Engineering and Technology (IRJET), Volume: 02 Issue: 09, Dec-2015, eISSN: 2395 -0056.

[2] Prof. Sudhir Kadam, Abhishek Saxena, Tushar Gaurav, "Android Based Wireless Notice Board and Printer", International Journal of Innovative Research in Computer and Communication Engineering, Vol. 3, Issue 12, December 2015, ISSN(Online): 2320-9801 ISSN (Print): 2320-9798.

[3] C.N.Bhoyar, Shweta Khobragade, Samiksha Neware, "Zigbee Based Electronic Notice Board", International Journal of Engineering Science and Computing, March 2017.
[4] Harleen Virdi, Manish Kr. Mukhija, "Multi Layer Data Security Through Data Obscuring", International Journal of Scientific Research \& Growth, Vol.3, Issue 1, pp. 1421, ISSN: 2456-1363, June 2018.

[5] S. Arulmurugan PP, S. Anitha PP, A. Priyanga PP, S. Sangeetha Priya," Smart Electronic Notice Board Using WI-FI", - International Journal of Innovative Science, Engineering \& Technology, Vol. 3 Issue 3, March 2016, ISSN $2348-7968$.

[6] Liladhar P. Bhamra, Abhinay P. Bhavsar, Dushyant V. Bhole, Dhanshree S. Gada, "Zigbee Based Notice Board”, IJARIIE, Vol-3 Issue-1 2017, ISSN(O)-23954396.

[7] Jaiswal Rohit, Kalawade Sanket, Kore Amod, Lagad Sanket, "Digital-Notice Board", International Journal of Advanced Research in Computer Engineering \& Technology (IJARCET) Volume 4 Issue 11, November 2015.

[8] Pooja Saini, Manish Mukhija, Prakash Dangi “" Design simulation of Efficient Character Recognition System Using Improved Pre Processing and Feature Extraction Process" ,Journal of The Gujrat Research Society ,Vol.21, Issue 16, pp. 1883-1889, ISSN: 0374-8588, December 2019.

[9] Modi Tejal Prakash, Kureshi Noshin Ayaz, Ostwal Pratiksha Sumtilal "Digital Notice Board", International Journal of Engineering Development and Research, Volume 5, Issue 2, 2017, ISSN: 2321- 9939.

[10] Suma M.N., Amogh H. Kashyap, Kajal D., Sunain A. Paleka, "Voice over Wi-Fi based smart wireless notice board", SSRG International Journal of Electronics and Communication Engineering (SSRG-IJECE) - Volume 4 Issue 6 - June 2017.

[11] P. Pavankumar, Sonita, S. Shruti, "Wireless scrolling LED display Notice board using WIFI", International Journal of Multidisciplinary - Innovation and Research Analysis (IJMIRA), Volume - 1; Issue 4; July-Sept 2017.

[12] Maru U., Sujediya G., Saini Y. "Color Image Encryption and Compression Using DCT in Joint Process", International Conference on Communication and Computational Technologies, Algorithms for Intelligent Systems. Springer, Singapore, 2021.

[13] Vishal Pratap Singh, Manish Kumar, Himanshu Arora, "Enhanced image security technique with combination of ARNOLD transformation and RSA algorithm", International Journal of TEST engineering and management, Vol.83, pp. 30550-30560, May/June, 2020, ISSN: 0193-4120 (Scopus).

[13] Ms. Sejal V. Gawande, Dr. Prashant R. Deshmukh "Raspberry Pi Technology" International Journal of Advanced Research in Computer Science and Software Engineering (IJARCSSE), Volume 5, Issue 4, April 2015.

[14] Rajeeb Lochan Dash, Mrs. A. Ruhan Bevi "Real-time Transmission of Voice over 802.11 Wireless Networks Using Raspberry Pi” International Journal of Engineering 
International Journal on Recent and Innovation Trends in Computing and Communication

ISSN: 2321-8169 Volume: 9 Issue: 5

DOI: https://doi.org/10.17762/ijritcc.v9i5.5483

Article Received: 31 March 2021 Revised: 22 April 2021 Accepted: 09 May 2021 Publication: 31 May 2021

Development and Research (IJEDR), 2014, Volume 2, Issue 1.

[15] Devender Kumar Dhaked, Yogender Kumar Sharma, Suman Bhakar, "Highly Secured Digital Image Watermarking Using LSB and DCT Combined Approach”, Design Engineering, 2021, Issue 6, pp. 1347 $-1356$.

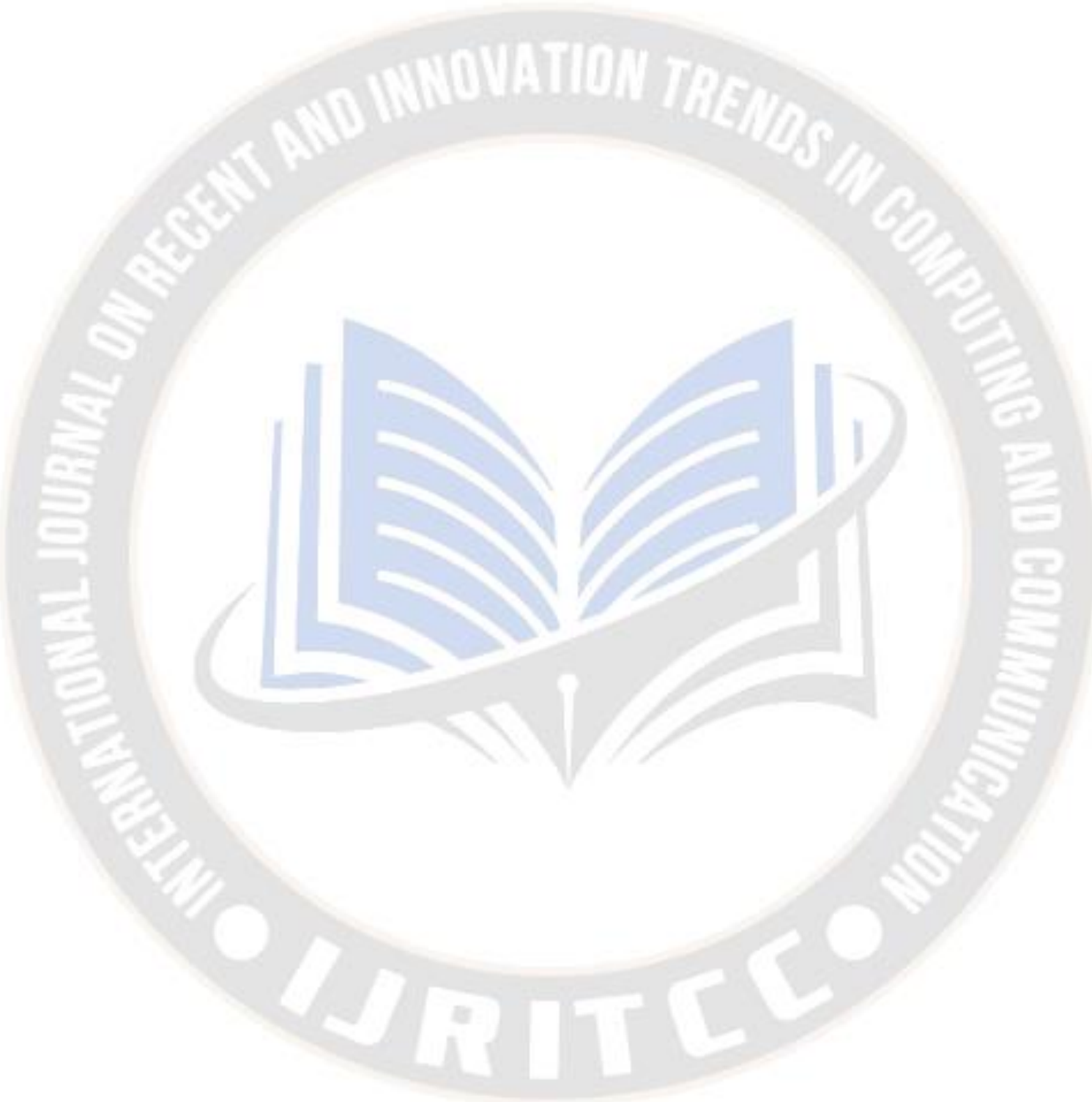

